\title{
NIR-reflective and hydrophobic bio-inspired nano-holed configuration on titanium alloy
}

\author{
Federico Belén ${ }^{a \S}$, A. Noel Gravina ${ }^{a \S}$, Marcelo Fabián Pistonesi ${ }^{a}$, Juan. M. Ruso $^{b}$, \\ Nicolás A. García ${ }^{c}$, Fernando Daniel Prado ${ }^{c}$ and Paula V. Messina ${ }^{a_{*}}$
}

(a) INQUISUR - CONICET, Department of Chemistry, Universidad Nacional del Sur, B8000CPB, Bahía Blanca, Argentina. (b) Soft Matter and Molecular Biophysics Group, Department of Applied Physics, University of Santiago de Compostela, 15782, Santiago de Compostela, Spain (c) IFISUR - CONICET, Department of Physics, Universidad Nacional del Sur, B8000CPB, Bahía Blanca, Argentina.

* Author to whom correspondence should be addressed. Tel: +54 291 4595159. Fax: +54 291 4595160. Electronic mail: pmessina@uns.edu.ar.

${ }^{\S}$ Federico Belén and A. Noel Gravina contributed equally to this work. 


\section{Digital imaging data acquisition}

For all images, three oval regions were defined as regions of interest, figure ESI1, and then used to construct frequency histograms of standard RGB colour levels.

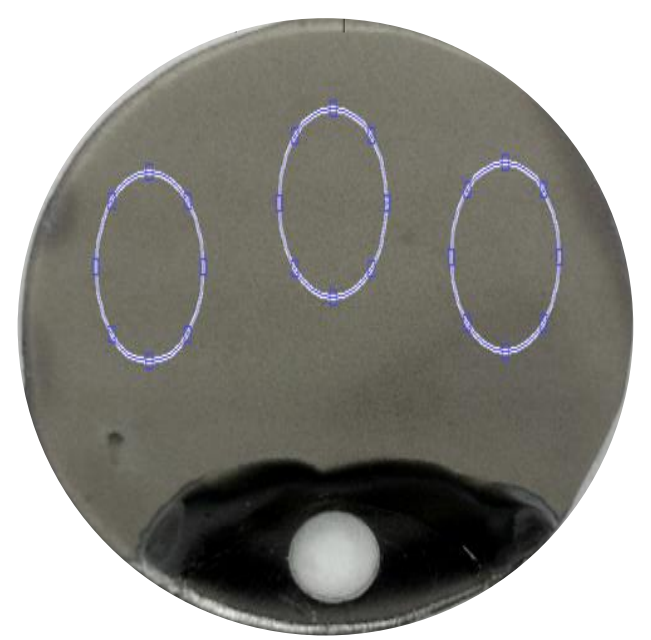

Figure 1SI. Surface image of a $\mathrm{TiO} 2$ nano-holed coated disk and the three oval regions defined as regions of interest (ROI).

To obtain the images at different angle of radiation incidence, a support was designed and printed in PLA for each angle. The support for an angle of incidence of $45^{\circ}$ is shown in figure 2SI as an example.

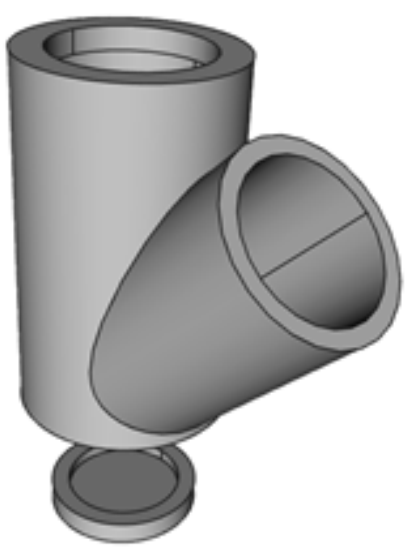

Figure 2SI. Support designed to take images of metallic samples after applied a light incidence angle of $45^{\circ}$ 
To take infrared (IR) images a system shown in figure 3ESI was assembled, which allowed the disks to be located in a closed place, removing the disturbance of external light.

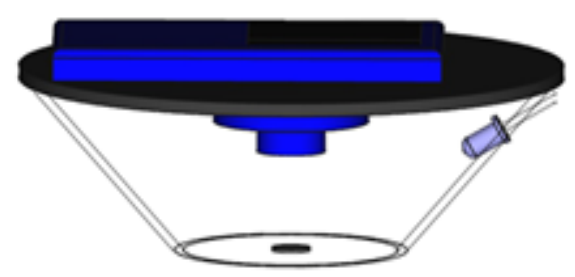

Figure 3SI. Home-made systems designed to acquire IR images.

Image acquisition of the interfaces solid/liquid/gas along static and dynamic contact angle measurements was performed by the home-made systems illustrated in figure 4SI.

a

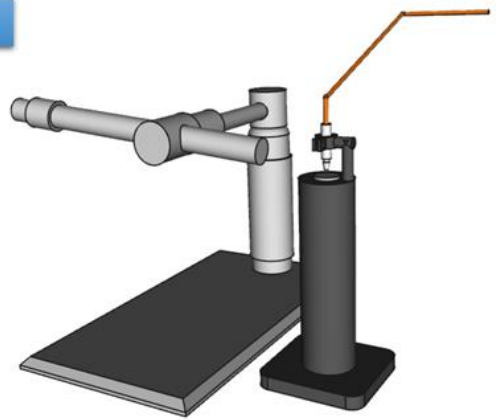

b

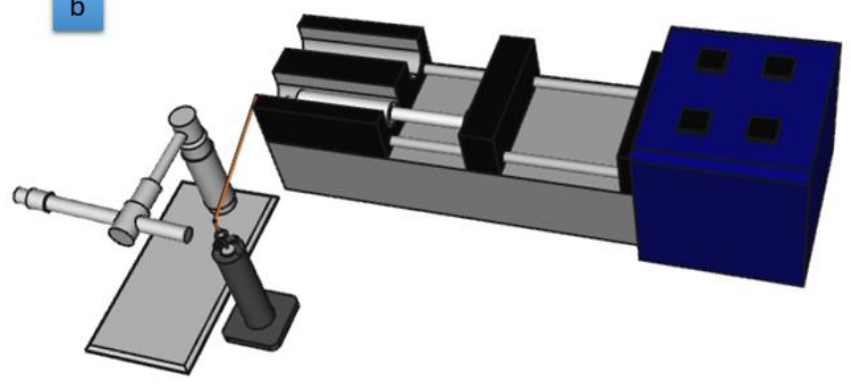

Figure 4SI. Home-made system used to obtain the interface liquid/solid/gas images. (a) Sample holder and digital microscope. (b) Sample holder, digital microscope, syringe and syringe pump. 


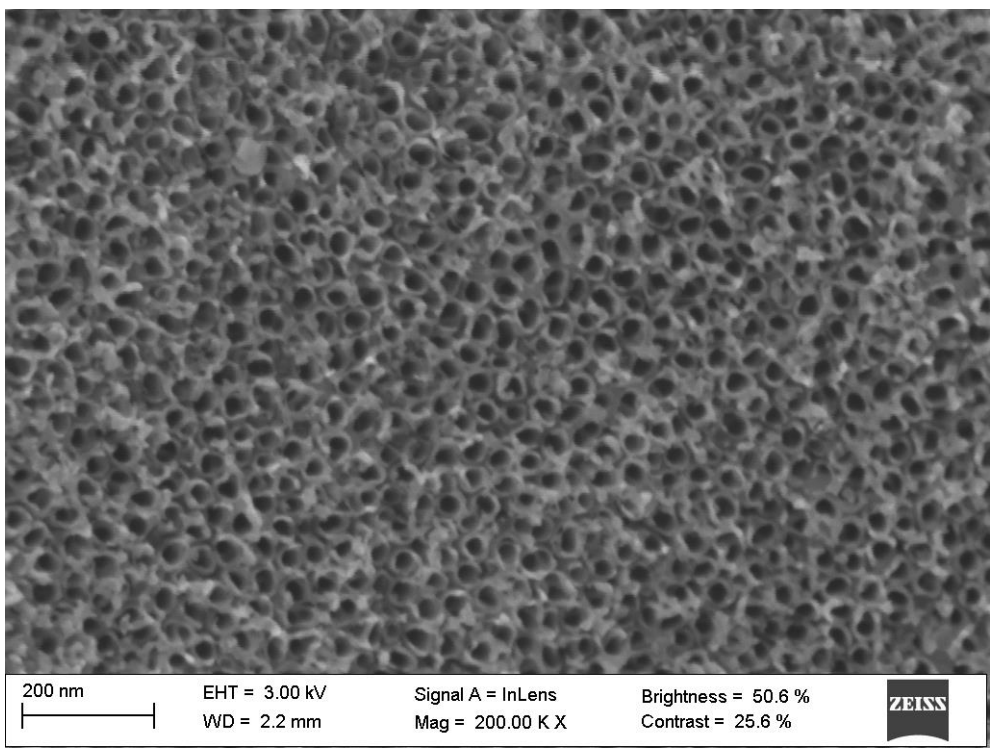

Figure 5SI. HR-SEM microphotograph of 7V anodized Ti6Al4V substrate.

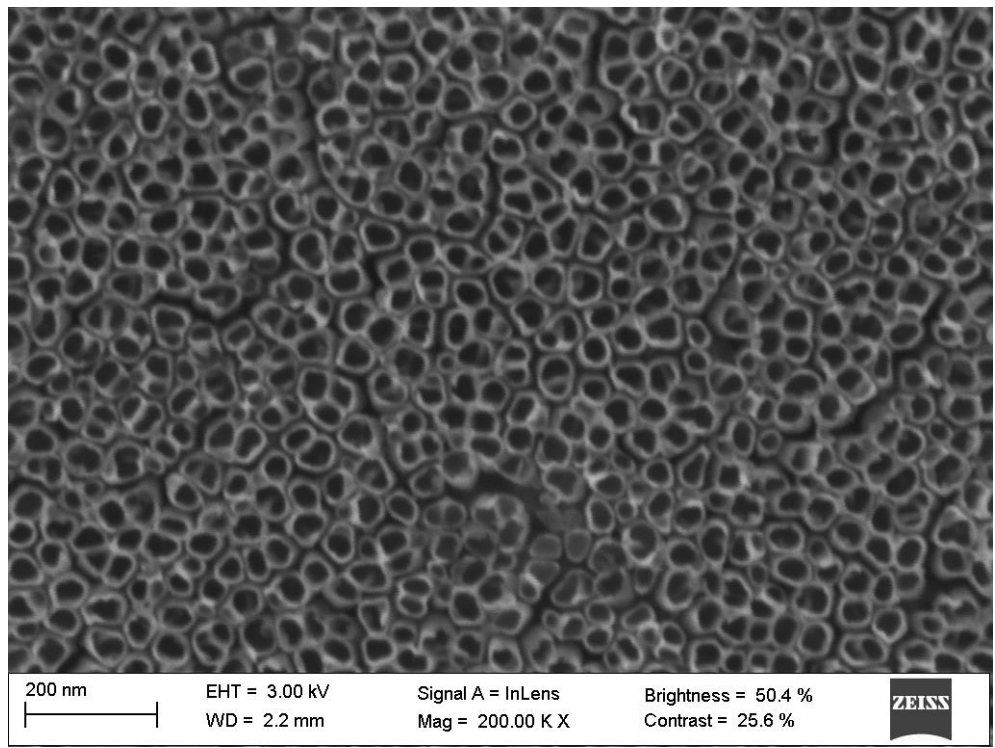

Figure 6SI. HR-SEM microphotograph of $10 \mathrm{~V}$ anodized Ti6Al4V substrate. 
Spectrum processing :

\begin{tabular}{l|ll}
\hline Element & Weight\% & Atomic\% \\
& & \\
F K & 5.62 & 12.66 \\
Al K & 4.65 & 7.37 \\
Si K & 0.08 & 0.12 \\
Ti K & 86.23 & 76.98 \\
V K & 3.41 & 2.87 \\
& & \\
Totals & 100.00 & \\
\hline
\end{tabular}
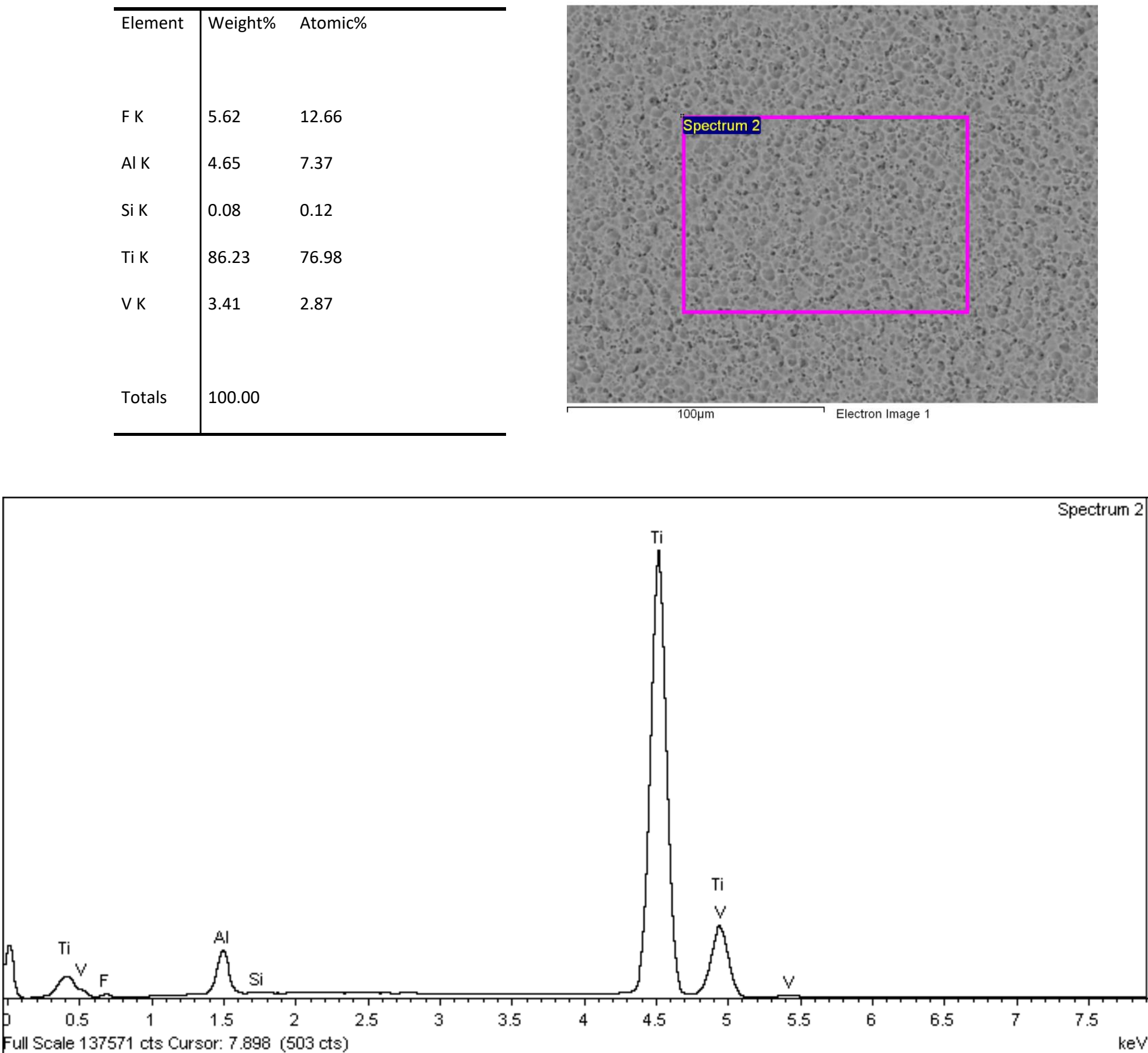

Figure 7SI. Elemental Microanalysis of 5V anodized Ti6A14V substrate. 
Spectrum processing :

\begin{tabular}{l|ll}
\hline Element & Weight\% & Atomic\% \\
O K & 10.61 & 25.12 \\
F K & 3.56 & 7.11 \\
Si K & 0.02 & 0.03 \\
Ti K & 85.04 & 67.28 \\
V K & 0.03 & 0.02 \\
& & \\
Totals & 100.00 & \\
\hline
\end{tabular}
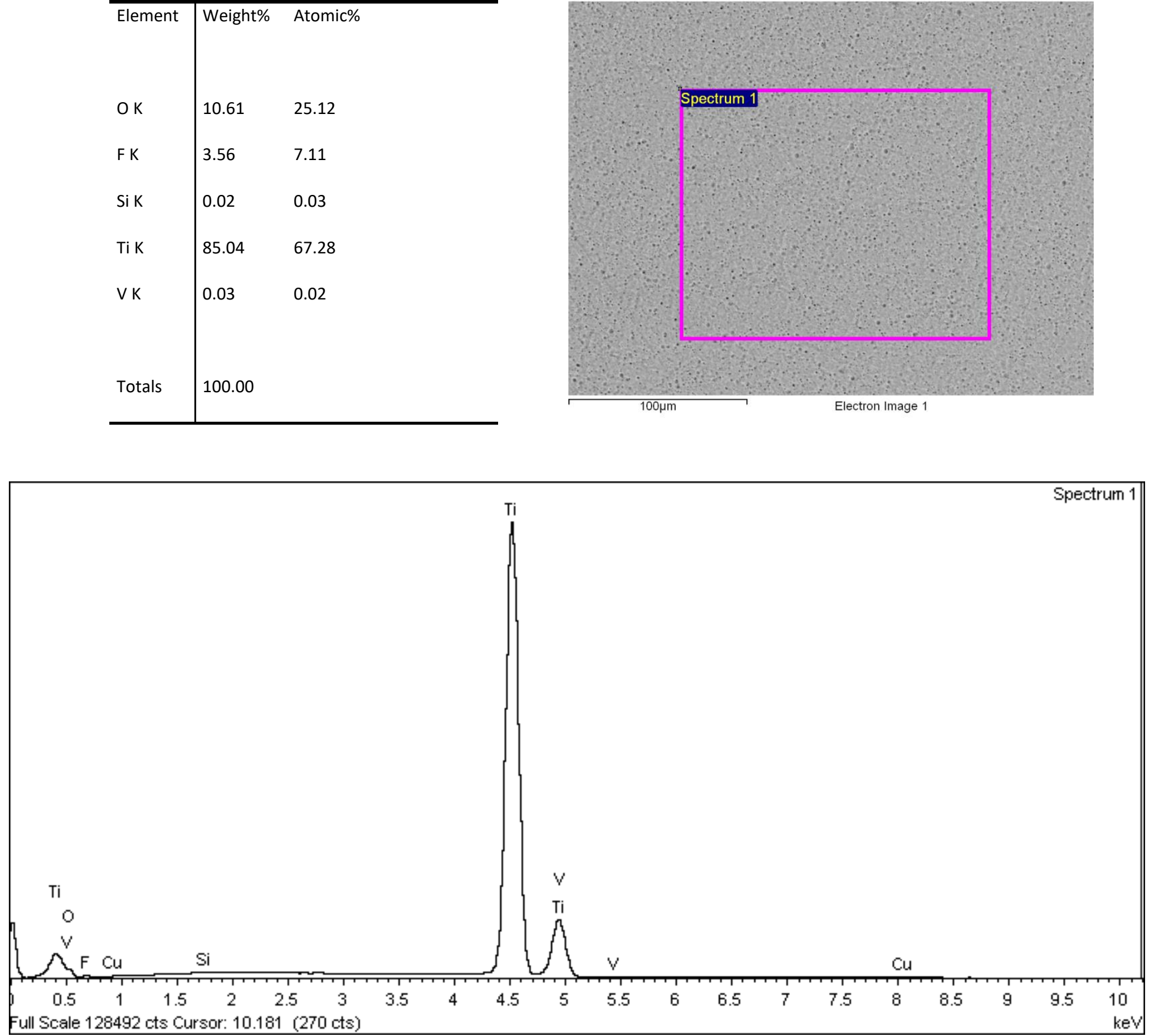

Figure 8SI. Elemental Microanalysis of 7V anodized Ti6Al4V substrate. 


\begin{tabular}{l|ll}
\hline Element & Weight\% & Atomic\% \\
Si K & 0.05 & 0.08 \\
Ti K & 98.99 & 99.18 \\
V K & 0.07 & 0.07 \\
Cu K & 0.89 & 0.67 \\
& & \\
Totals & 100.00 & \\
\hline
\end{tabular}

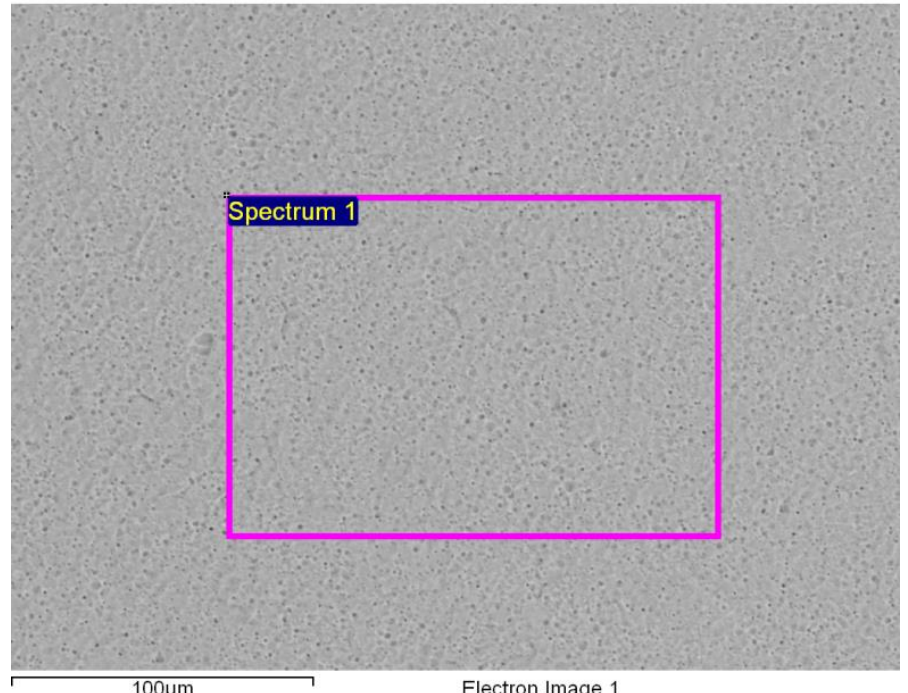

Electron Image 1

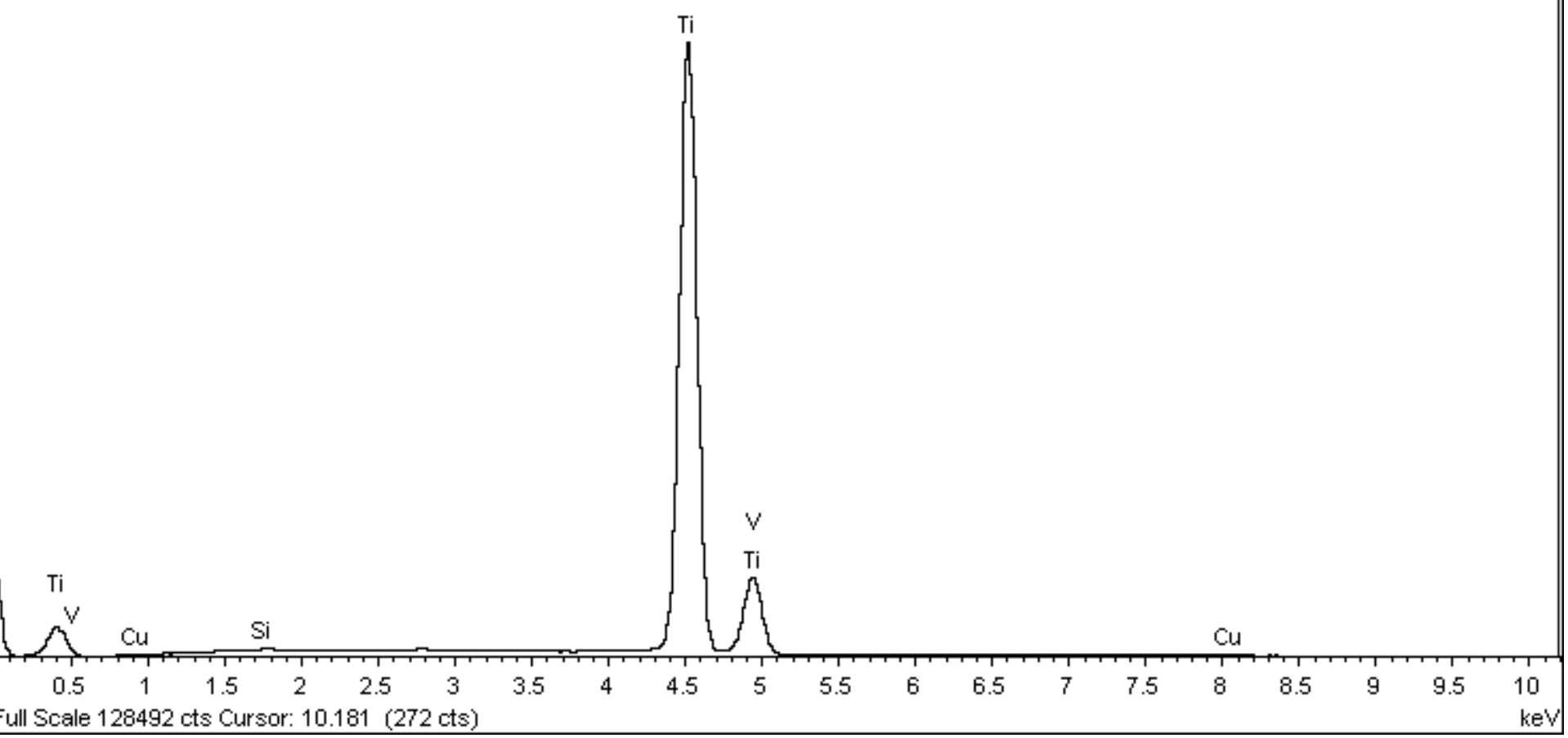

Figure 9SI. Elemental Microanalysis of 10V anodized Ti6Al4V substrate. 

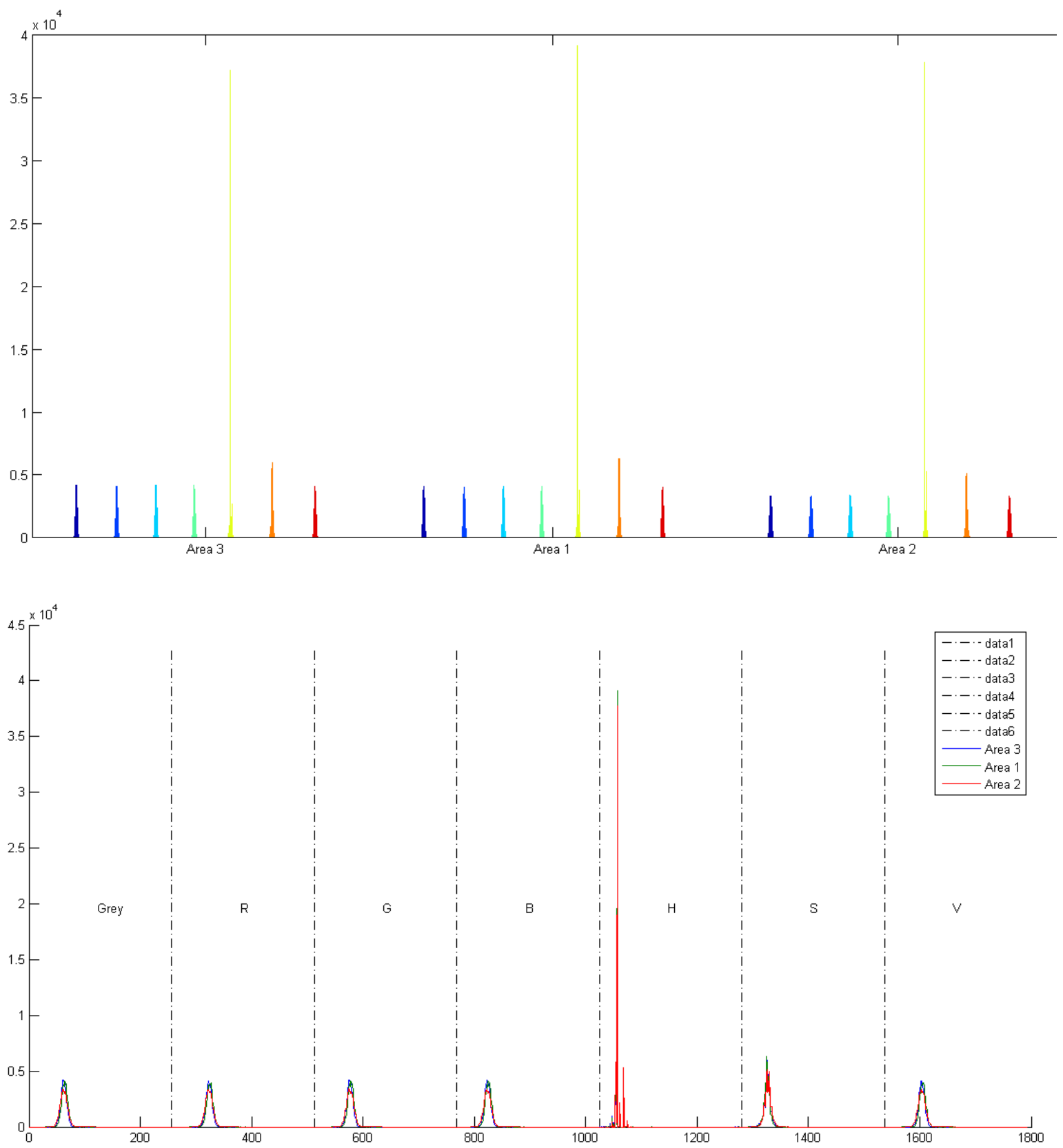

Figure 10SI. Frequency histograms of RGB colour levels of the three selected regions (ROI) displayed in figure 1SI after image processing. Each ROI correspond to an analysed area. 


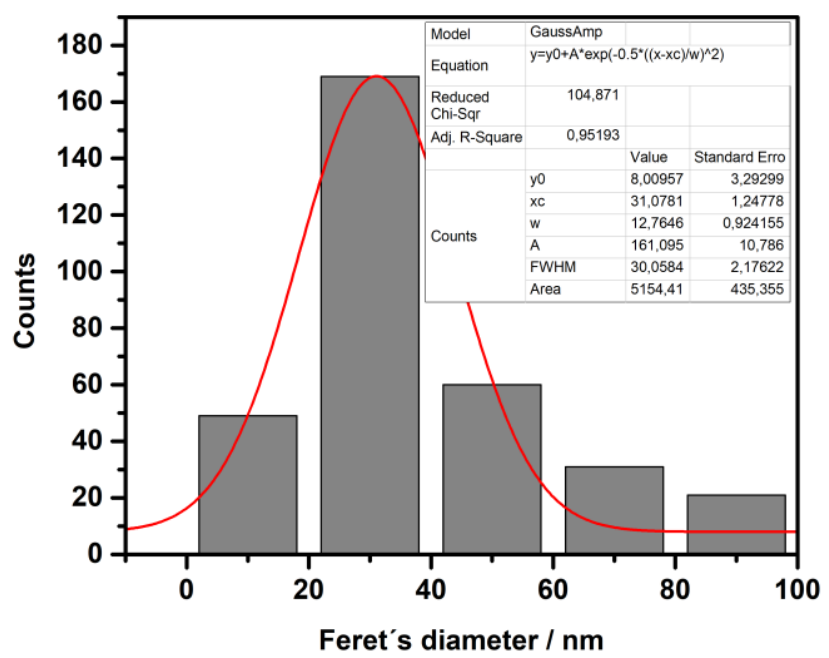

Figure 11SI. Frequency histograms of Feret's diameter determined after inspection of 5V $a$-Ti6A14V HR-SEM microphotographs.

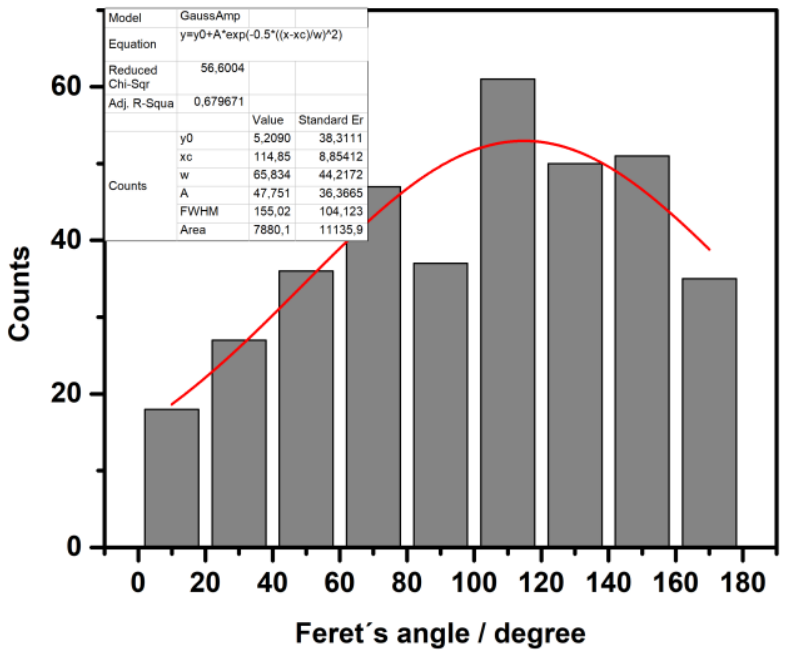

Figure 12SI. Frequency histograms of Feret's angle determined after inspection of 5V $a$ Ti6Al4V HR-SEM microphotographs. 


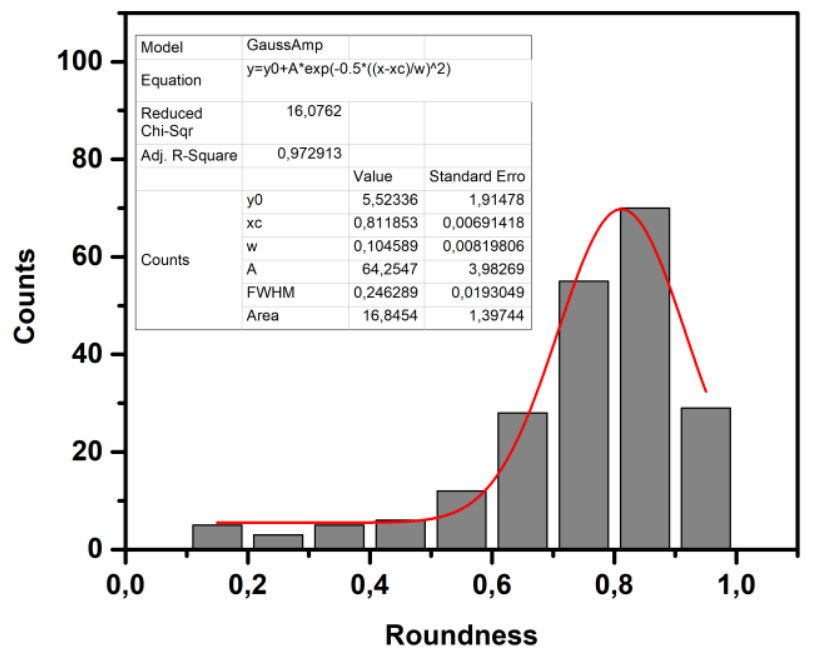

Figure 13SI. Frequency histograms of Roundness determined after inspection of $5 \mathrm{~V} a$ Ti6Al4V HR-SEM microphotographs.

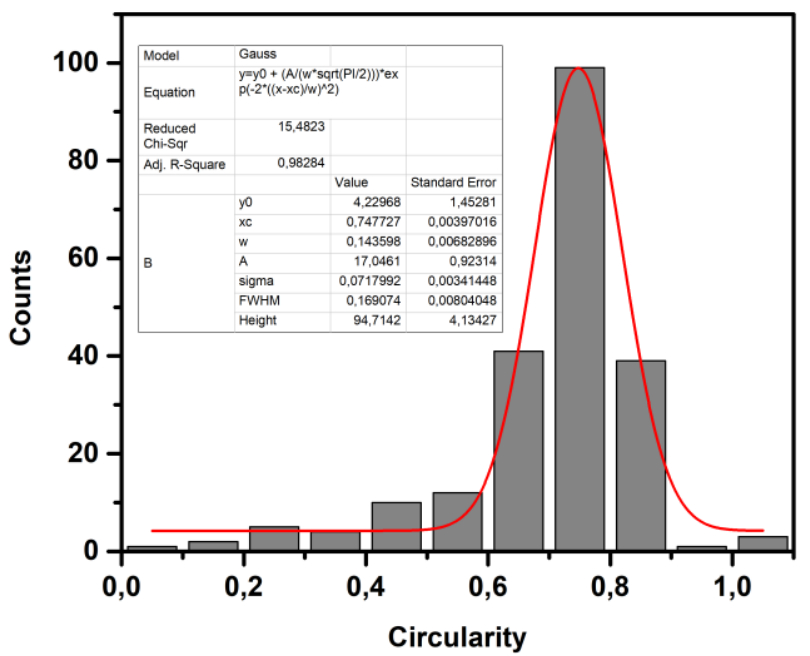

Figure 14SI. Frequency histograms of Circularity determined after inspection of $5 \mathrm{~V} a$ Ti6Al4V HR-SEM microphotographs. 


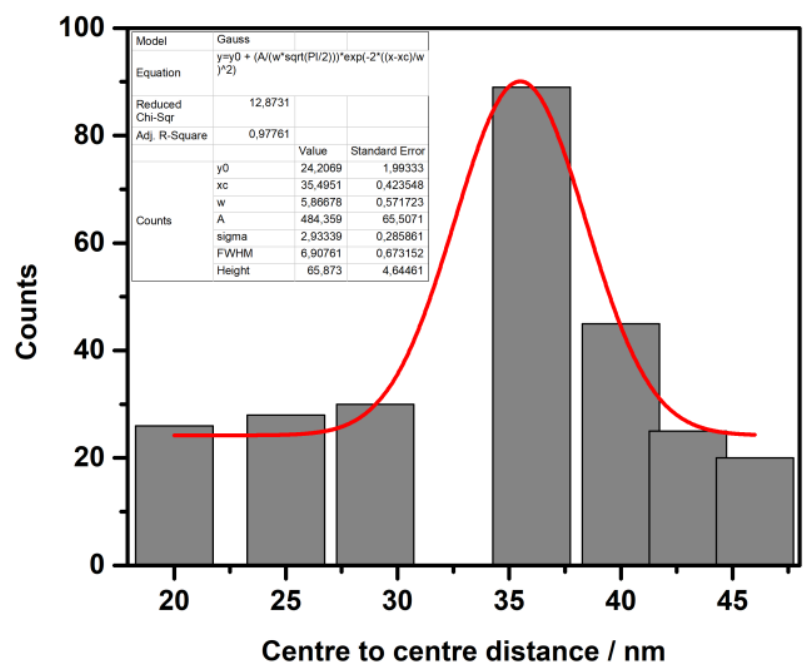

Figure 15SI. Frequency histograms of centre to centre distance between nano-holes, determined after inspection of 5V $a$-Ti6Al4V HR-SEM microphotographs.

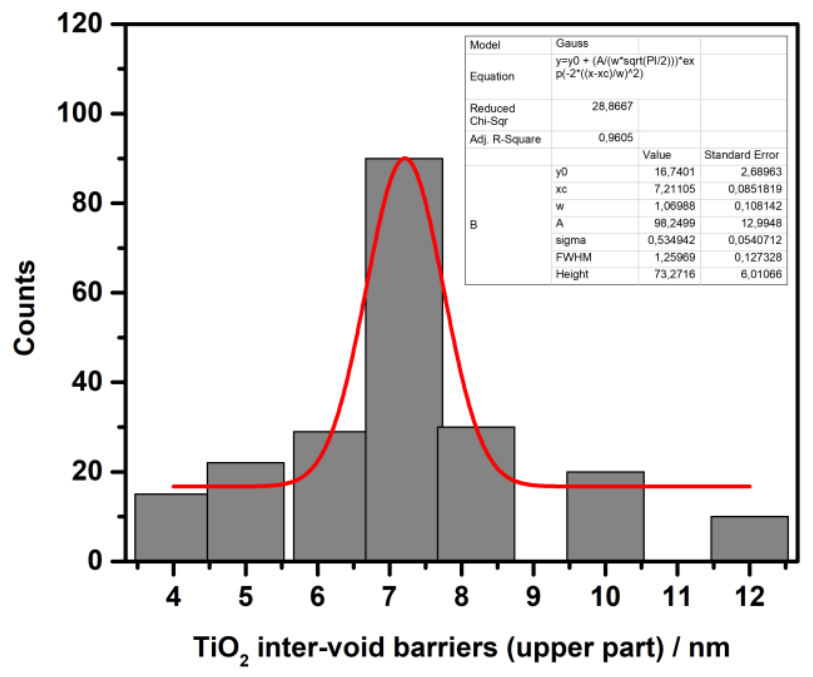

Figure 16SI. Frequency histograms of the inter-void barrier distance (upper part) in $\mathrm{TiO}_{2}$ nano-holed structure, determined after inspection of $5 \mathrm{~V} a$-Ti6Al4V HR-SEM microphotographs. 


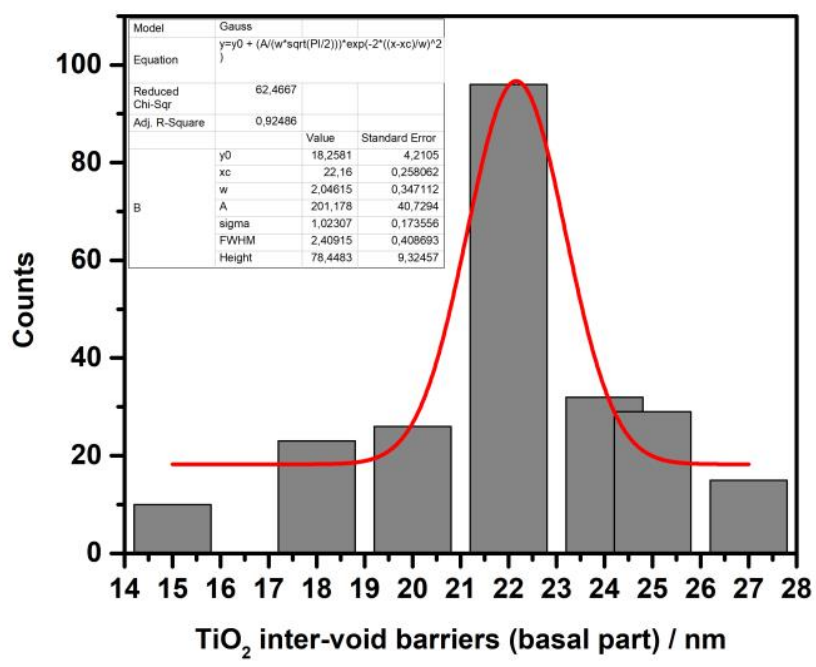

Figure 17SI. Frequency histograms of the inter-void barrier distance (basal diameter) determined after inspection of 5V $a$-Ti6Al4V HR-SEM microphotographs.

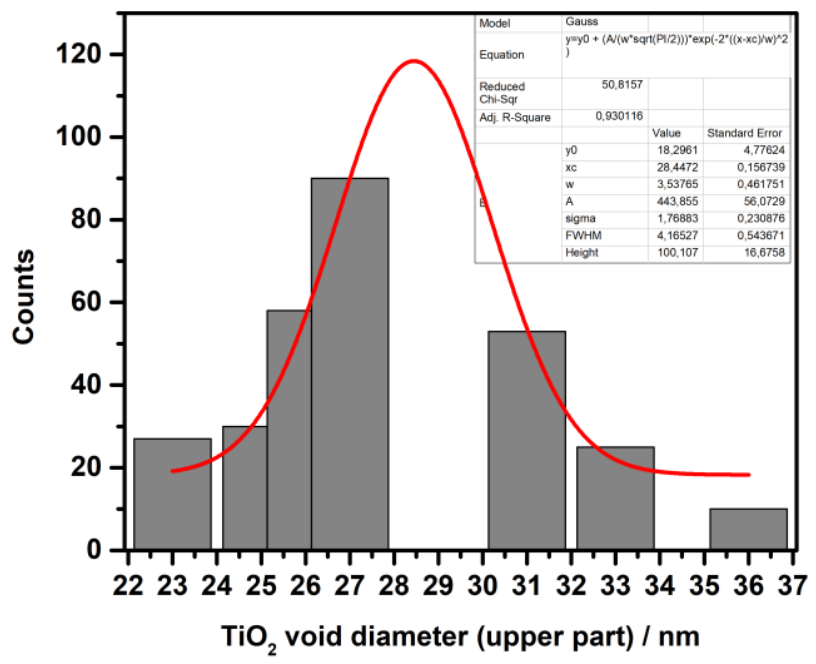

Figure 18SI. Frequency histograms of the void diameter (upper distance) determined after inspection of 5V $a$-Ti6Al4V HR-SEM microphotographs. 


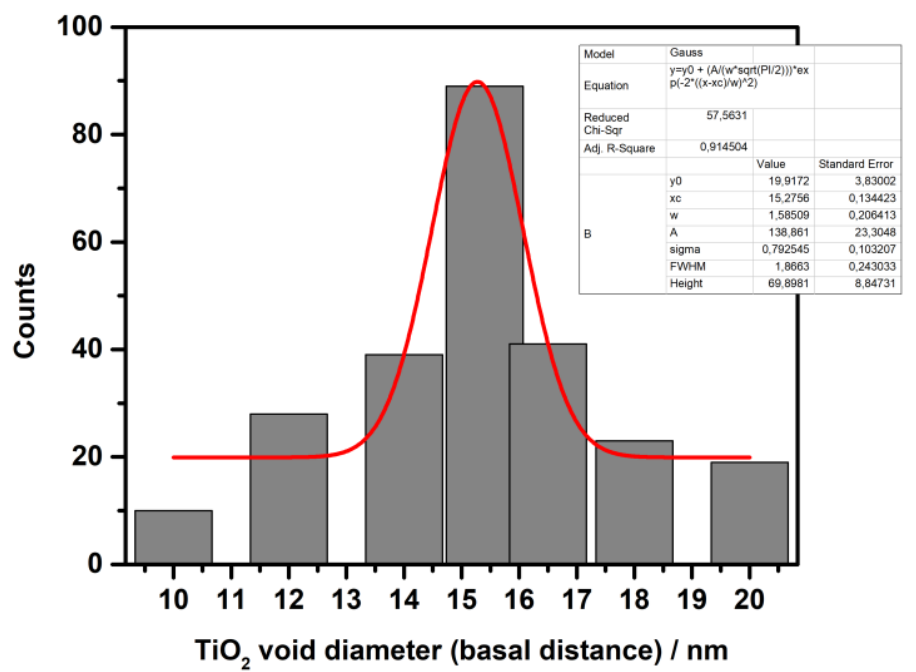

Figure 19SI. Frequency histograms of the void diameter (basal distance) determined after inspection of 5V $a$-Ti6Al4V HR-SEM microphotographs. 


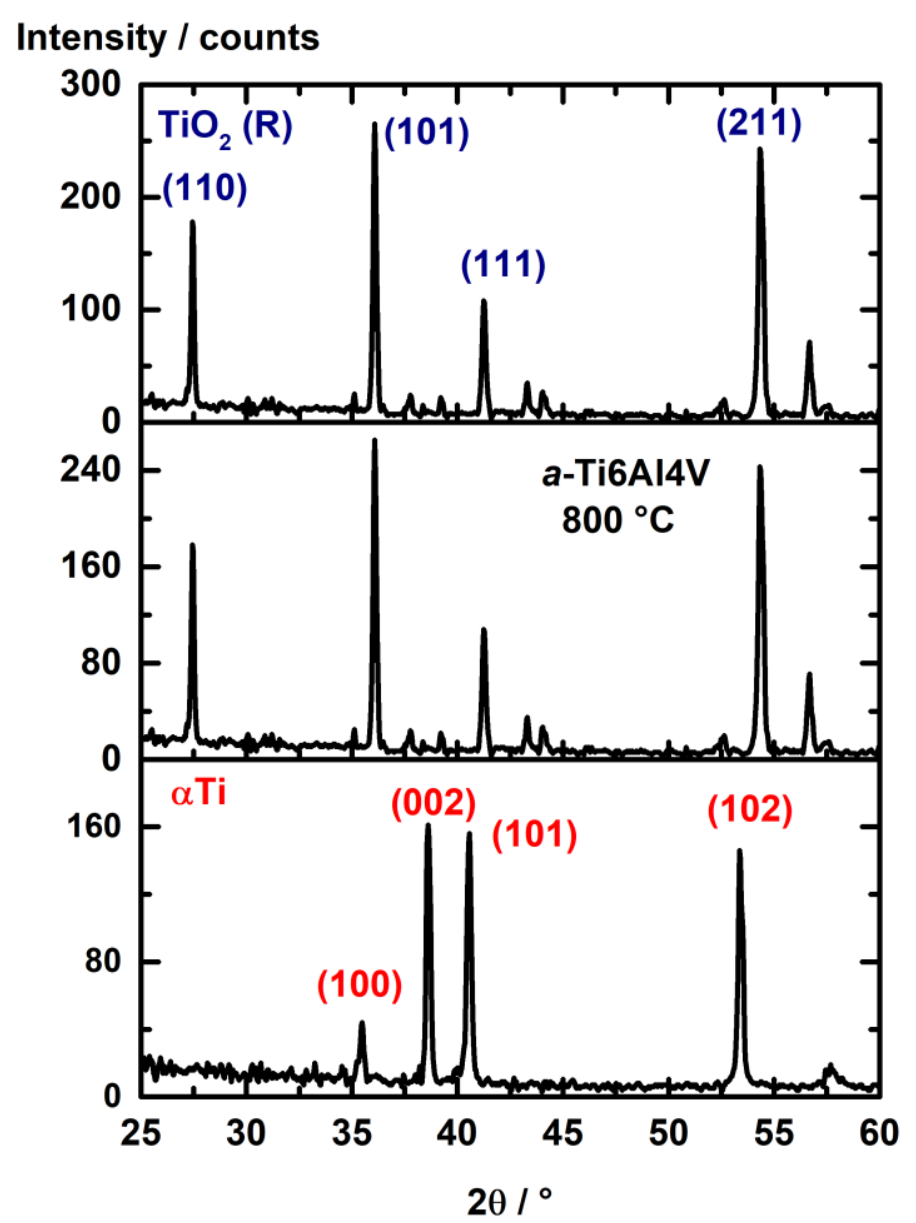

Figure 20SI. DRX of $a$-Ti6Al4V sample calcined at $800^{\circ} \mathrm{C}$. Standards (JCPDS) cards $\mathrm{n}^{\circ}$ 44-1294 $(\alpha-\mathrm{Ti}), 75-1752\left(\mathrm{TiO}_{2}\right.$, rutile $)$ and 21-1272 $\left(\mathrm{TiO}_{2}\right.$, anatase $)$ were used as references. 


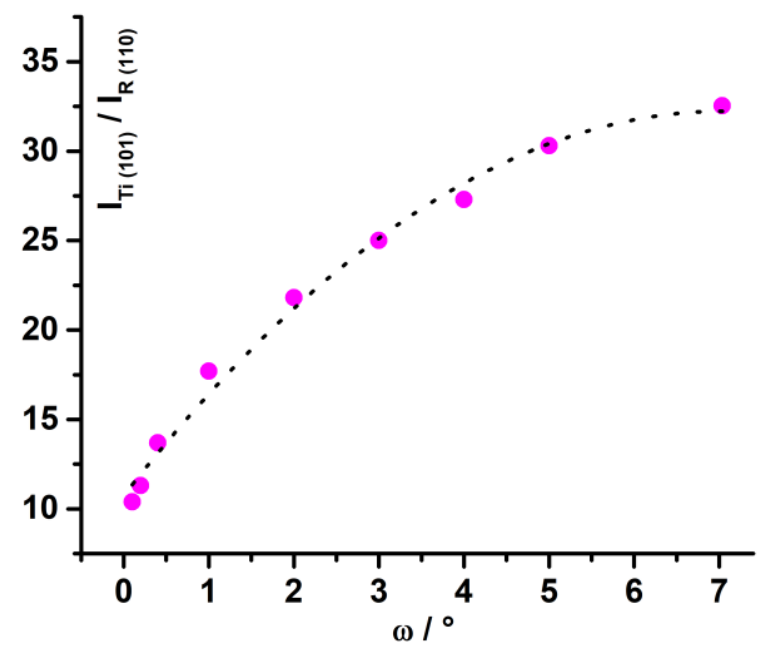

Figure 21SI. Variation of the characteristic of $\alpha-\mathrm{Ti}(\mathrm{hkl})=(101)$ and $\mathrm{TiO}_{2}$ rutile $(\mathrm{hkl})=$ (110) intensity peak with $\omega$ along GIDRX measurements of $a$-Ti6Al4V sample annealing at $500^{\circ} \mathrm{C}$. Standards (JCPDS) cards $\mathrm{n}^{\circ}$ 44-1294 ( $\alpha$-Ti), 75-1752 $\left(\mathrm{TiO}_{2}\right.$, rutile) and 21-1272 $\left(\mathrm{TiO}_{2}\right.$, anatase) were used as references.

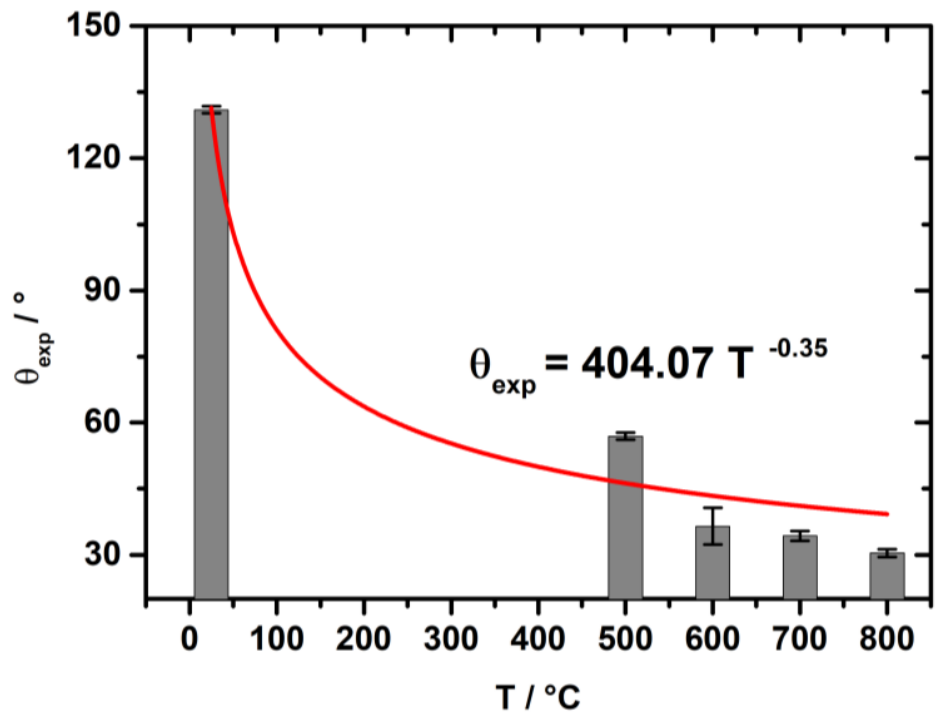

Figure 22 SI. Annealed surface temperature $\left(\mathrm{T} /{ }^{\circ} \mathrm{C}\right)$ dependence of experimental static water contact angle. 